\title{
Design and Implementation of Color Mixing and Painting Automatic Machine
}

\author{
Abdalftah H. Mohammed ${ }^{1, *}$, K.M. Elnitefa ${ }^{1}$, H.A. Mohamed ${ }^{1}$, A.Y. Mohammed and Y.M. Alkasim ${ }^{12}$ \\ 1 Electrical and Electronics Engineering Department, Omdurman Islamic University, Omdurman, Sudan \\ 2 School of Electrical Engineering (Communications) from Karari University \\ * Corresponding author: Abdalftah. H. Mohammed (abdftah1994@gmail.com ).
}

Article history: Received 05 March 2019, Received in revised form 26 October 2019, Accepted 13 January 2021

\begin{abstract}
In this paper we represent a design and implementation of color mixing and painting machine, useful for many industrial applications, efficiently and lower the cost. The machine mixes Red, Green, and Blue RGB colors with a base to produce the required color defined by the user, and then pump it through pipes in painting machine with a robotic arm, this painting machine will do the painting job. The model is designed and implemented using a Programmable Logic Controller (PLC-S7300) which controls the process of mixing the required color, these colors is filled in container tanks, five tanks, three for each RGB colors, one for the base, and one for the cleaning liquid. The mixer uses a DC motor to rotate mixing fins. Although the robotic arm uses 5 DC motor to move the arm joints.
\end{abstract}

Keywords: PLC; RGB; HMI; Painting; Mixing; Robotic arm; Color.

\section{INTRODUCTION}

Color mixing process is an operation where casting two or more colors in order to compose a new color. Using cumulative experience human had gained a whole new combination of colors.

As technology progress led to appearance the controllers which make lots of difficulties a lot easier, researcher had made use of these controllers in order to mix colors with a certain percentages and with high accuracy.

After color mixing the new color will be pumped according to the operation chosen using HMI through a pipe for painting process.

As technology process and the appearance of Artificial Intelligence AI science which led to a production of robotics capable of achieving preprogramed tasks, these tasks are common to be achieved by human manually. However, a lot of these tasks require accuracy and fast movements in order to be fulfilled in a suitable time, sometimes present hazards to the operator himself such as exhaling the painting.
Therefore, a robotic arm has been designed, which capable of achieving the painting process in small time interval and with high accuracy. This arm designed to work in various environments and controlled using PLC [1] [2].

The propose design of the machine containing basic tank, color tank and cleaning tank [3]. Also, a special container for the mixing process and robotics for painting process.

This paper will lead to design smart machine which capable and achieving mixing and painting colors.

\section{OVERALL SYSTEM DESIGN}

The proposed design and implementation of the machine consists of four tanks, divided into upper level tanks which contains of the base tank, using three base types, colored using coloring materials in other three tanks containing these materials (Red, Green, and Blue) RGB. Besides clean tank, which hold cleaning liquid. Lower tank, is the mixing tank, filled with the required color acquired by the user through Human 
Machine Interface HMI.

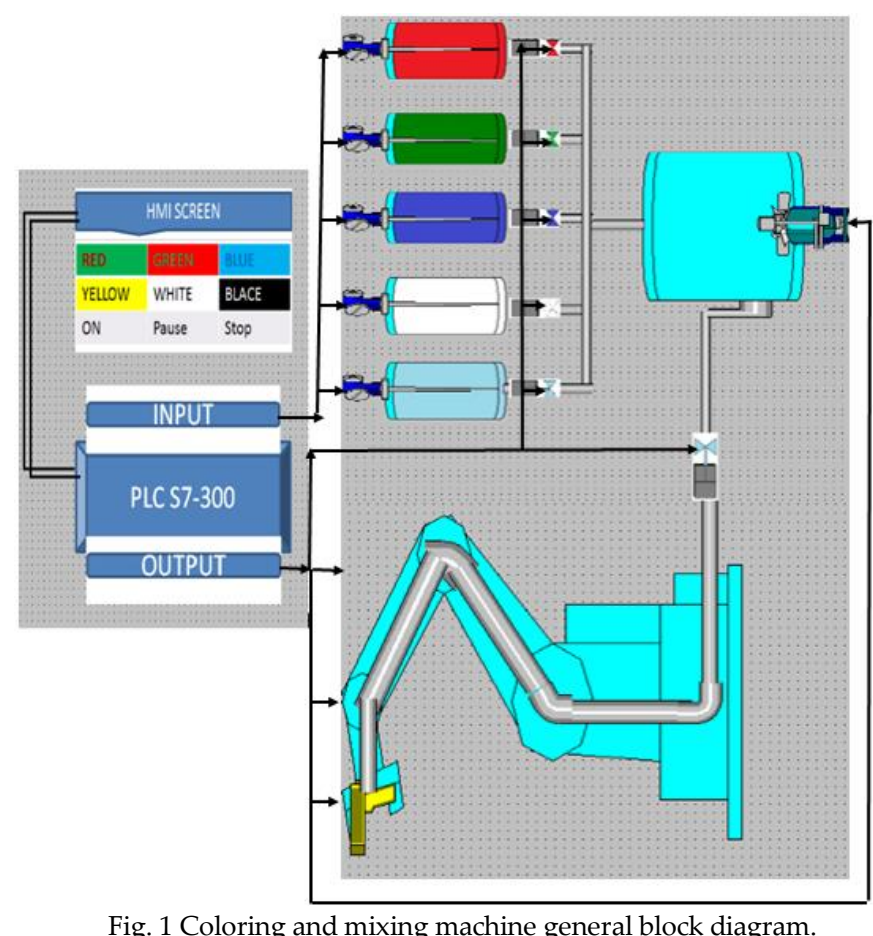

The second task of the machine is the painting after mixing the required color. Therefore, a robotic arm attached into the machine frame operates using 5-volt DC motors.

Fig 1 illustrates the general function diagram of the machine and its different part interconnection.

\section{WORKING PRINCIPLE}

In order to mix a certain color, this requires the user to interact with many selection procedures which will be shown in front of him in HMI.

Color selection procedures start with choosing the base color among three types (A, B, and C). According to this selection, the amount of the base is determined. Due to this procedure the base tank valve is opened and the base pump will be activated. However, to open the valve and make the pump work, the base tank level must be at least equal to the required value, which monitored using the tank level sensor. Otherwise, an alarm will appear in the screen.

The next step is choosing the required color; the user will select the color from a list monitored in the HMI. According to this selection and based on RGB standard coloring system, three coloring tanks valves will be opened and its pumps will push the color in pipes. The valves will be opened for a certain time interval, again the required amount of color must be less than the tank container, otherwise an alarm will appear again.

The final mixing step is mixing the coloring RGB materials with the base in order to compose the required color.

The painting process uses five joint robotic arm programed using Programmable Logic Controller PLC to work in fixed dimensions piece $(x, y, z)$. The arm starts from a home position point, and move into a starting point, at this point the valve and pump will start operating. The Arm will then move vertically to paint vertical line and then horizontally to a different position, this operation will be repeated until all the piece is colored. At the end, the valve and the pump will switch off, and the arm will move back to the home position.

After finishing the painting process, and before selecting a new color, the mixing tank must be cleaned from the previous color. Therefore, the cleaning liquid will be pumped.

\section{HARDWARE DESCRIPTION}

Hardware used to design and implement this project can be divided into three categories. Outputs, which are the valve allowing base, coloring materials, cleaning liquid, as well as the composed final color moving through pipes, besides, pumps pushing all liquids into these pipes, and mixing motors, finally relays switching DC motors on and off which move the robotic arm joints. Inputs that monitor the current status of the system and allow the controller to perform its tasks.

A controller which enables and disable a certain output according to inputs and stored values [3].

Above all, there are start, stop, and emergency indicators, as well as start, stop and emergency buttons. Fig. 2 shows the connection of inputs and outputs with the controller and the labels of connection.

\section{A) Controller}

This machine was controlled using PLC Siemens Simatic Step7-300 [4] which is cheap among other PLCs, these module specifications as shown in table 1 . 
TABLE 1: PLC SIEMENS SIMATIC STEP 7-300 [4]

\begin{tabular}{|c|c|}
\hline Parameter & Value \\
\hline Number of Inputs & 16 \\
\hline Number of Outputs & 16 \\
\hline Operating voltage & $24 \mathrm{v}$ \\
\hline Operating temper & $\mathrm{Up} \mathrm{to} 40{ }^{\circ} \mathrm{C}$ \\
\hline $\begin{array}{c}\text { Input Current(rated } \\
\text { value) }\end{array}$ & $850 \mathrm{~mA}$ \\
\hline $\begin{array}{c}\text { Output current (rated } \\
\text { value) }\end{array}$ & $500 \mathrm{Ma}$ \\
\hline
\end{tabular}

\section{B) Inputs}

As input devices, push button switches have been used to start and stop the system. Beside emergency switch, for measuring tanks level and controlling mixing process level five level switches has been chosen. These switched selected as capacitive level sensor for the design with specifications as shown in table 2, however due to limitation in budget and local market, obtaining these switches was difficult. Instead normal push buttons have been used.

TABLE 2: capacitive level switch specifications

\begin{tabular}{|l|l|}
\hline Parameter & Value \\
\hline Temper & $\mathrm{T}<-80{ }^{\circ} \mathrm{C} /-112{ }^{\circ} \mathrm{F}$ or \\
& $\mathrm{T}>+200{ }^{\circ} \mathrm{C} /+392{ }^{\circ} \mathrm{F}$ \\
\hline Pressure & $>100 \mathrm{bar} / 1450 \mathrm{psi}$ \\
\hline Measuring range & $>10 \mathrm{~m} / 3.2 \mathrm{ft}$ \\
\hline
\end{tabular}

\section{C) Outputs}

Three indicator lambs for system status (stop, working, and emergency), five solenoid valves one valve for each tank. These valves have specification shown in Table 3.

Table 3: solenoid valve specification

For pushing colors and base into mixing tank a pump has been used which has specification as shown in Table 4.

The mixer uses a DC motor to rotate a mixing fan this motor has specifications shown in table 5

A robotic arm used for painting uses DC motor for moving the joints and relays for control this movement steps, both DC motors and relays has specifications shown in table 6 .

\section{SOFTWARE SPECIFICATION}

In order to control the system, the PLC needs to be programed using Simatic manager software tool. The program follows the algorithms shown in Fig. 3 which represent the color mixing process, and Fig. 4a, Fig. 4b illustrate the painting process.

Human Machine Interface HMI used as input for selecting colors which programmed using WINCC flexible software tool. However, this HMI cannot be implemented, for the implementation a laptop has been used instead

In order to control the system, the PLC needs to be programed using Simatic manager software tool. The program follows the algorithms shown in fig 3 which represent the color mixing process, and fig 4-a, fig 4-b illustrate the painting process.

Human Machine Interface HMI used as input for selecting colors which programmed using WINCC flexible software tool. However, this HMI cannot be implemented, for the implementation a laptop has been used instead of it.

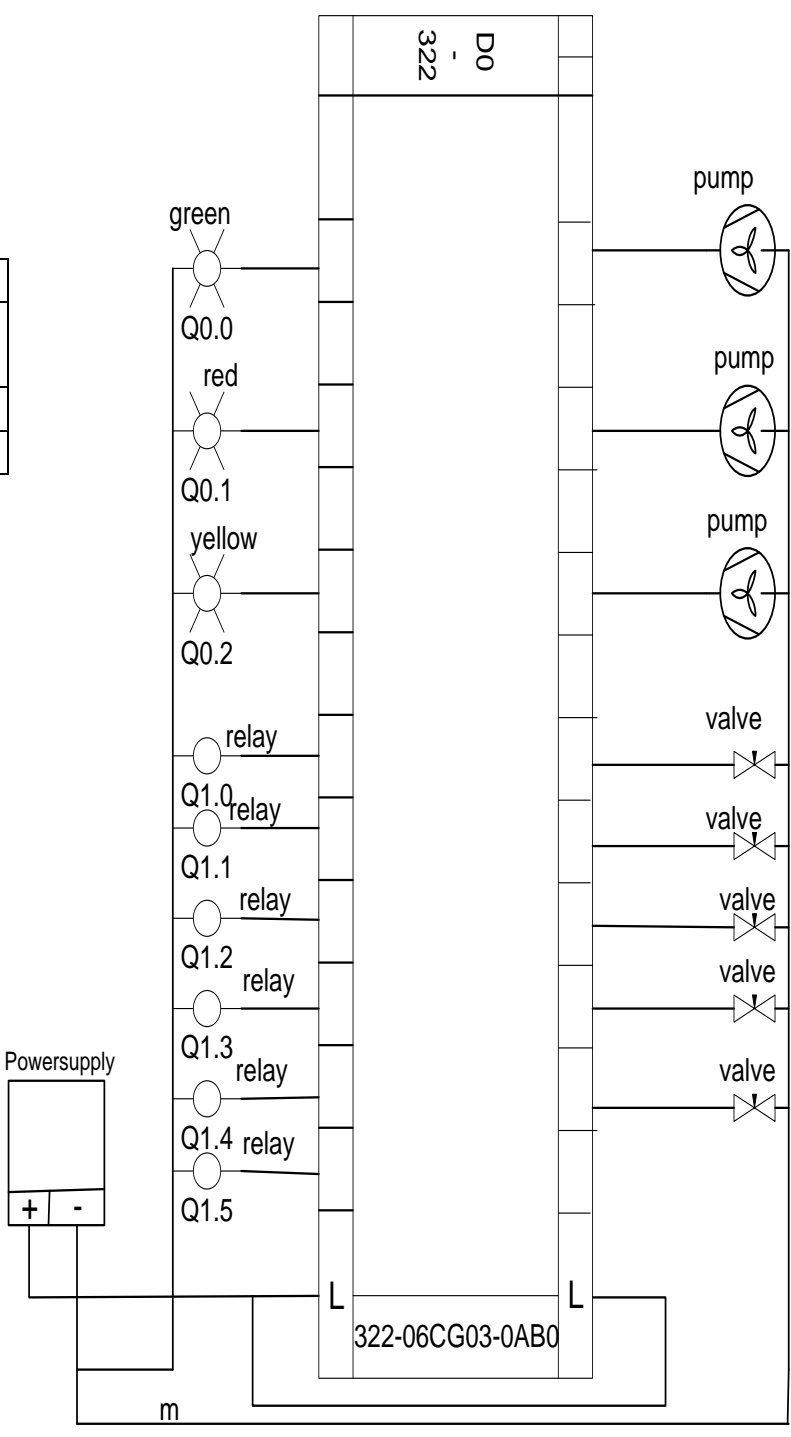

Fig. 2 Connection of inputs and outputs with the controller and the labels of connection 


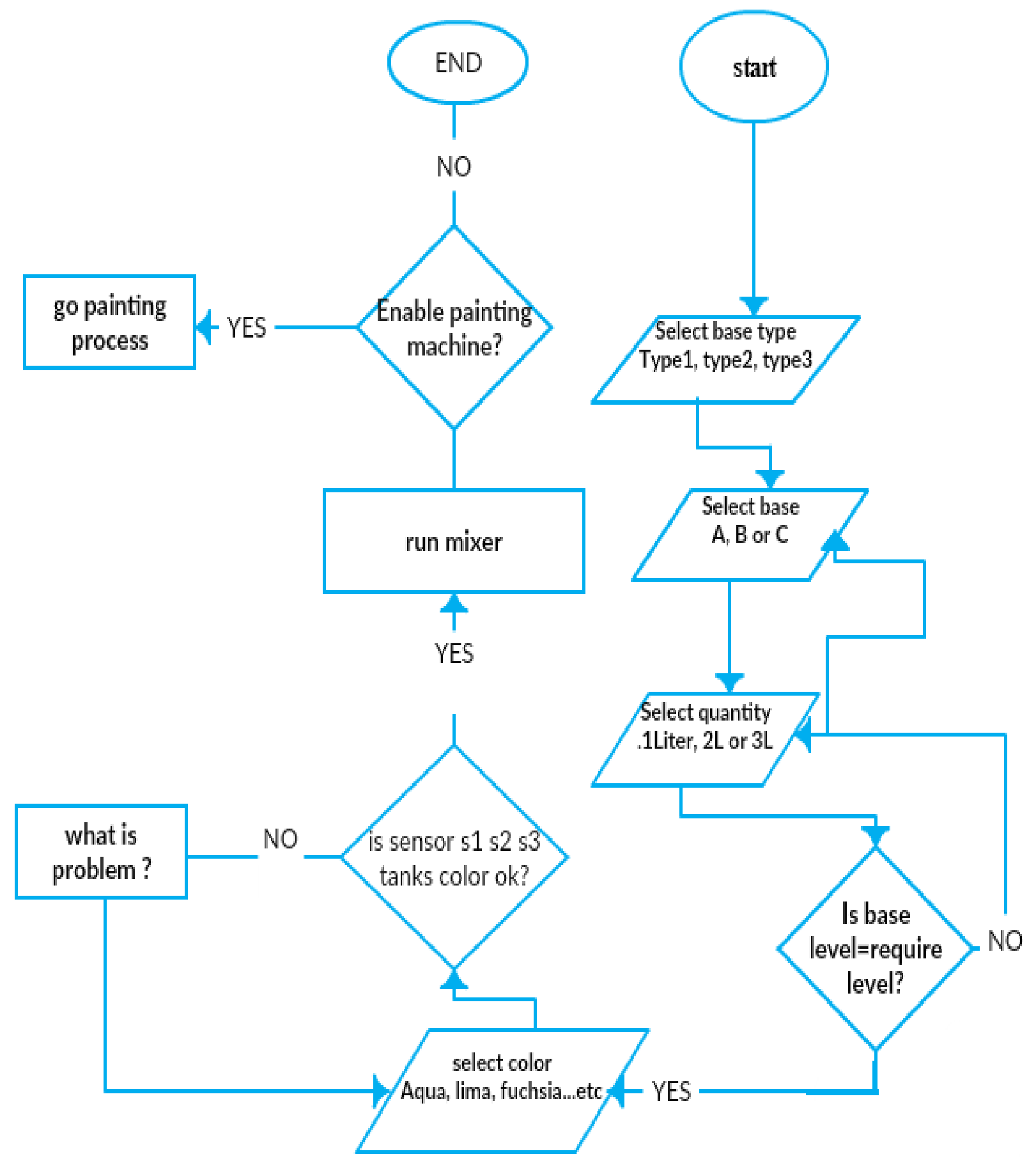

Fig. 3: Color mixing flowchart 


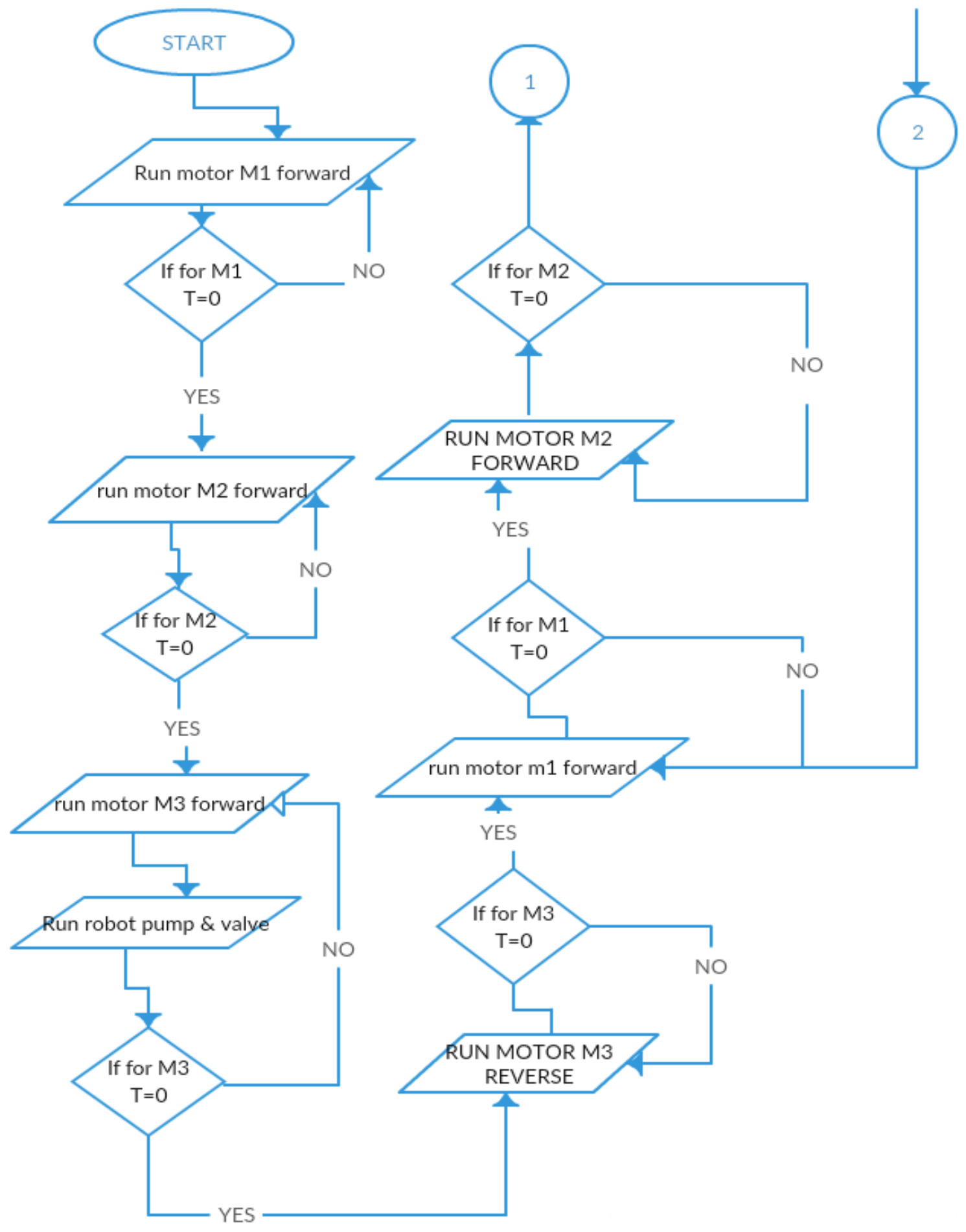

Fig. 4a painting process flow chart 


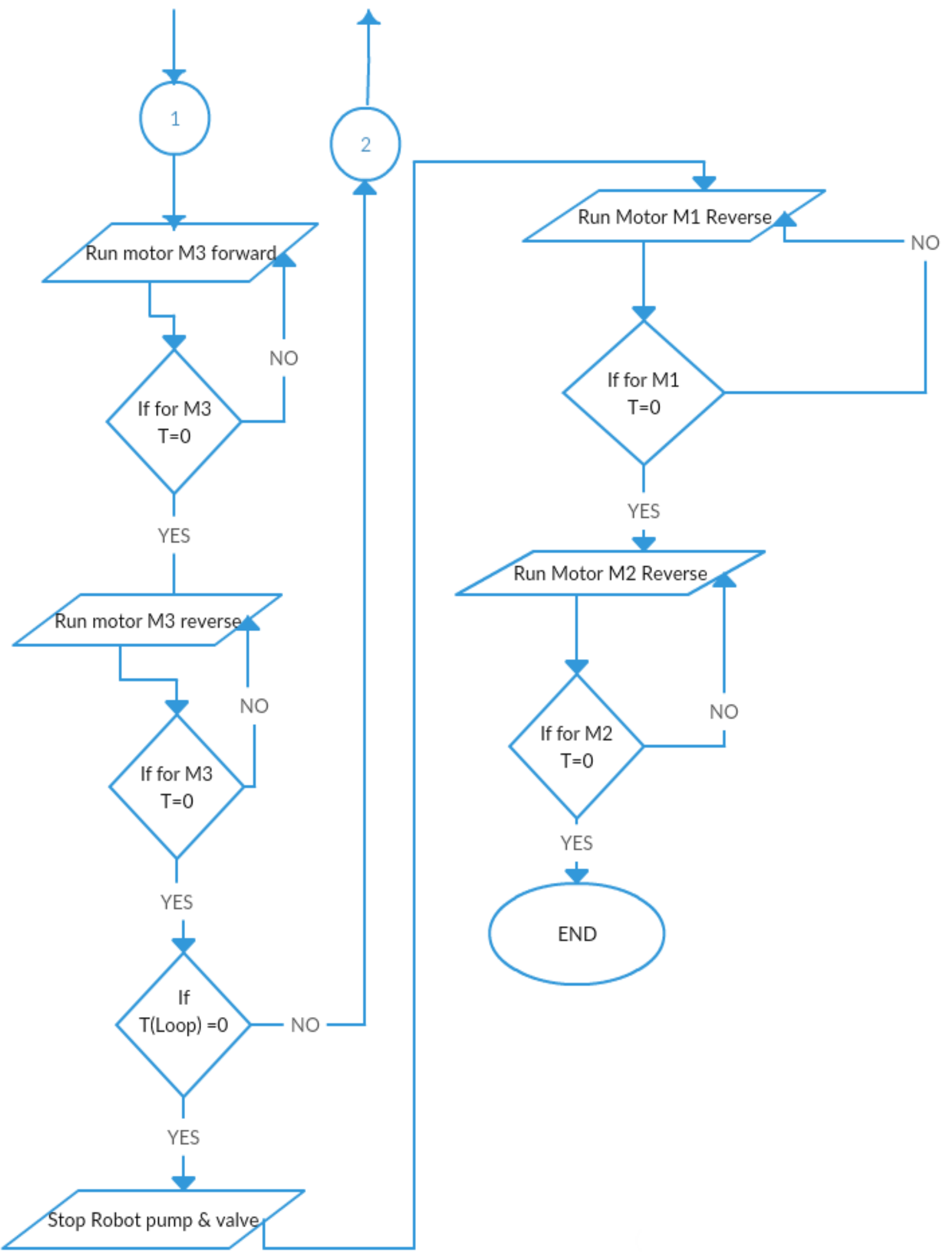

Fig. $4 \mathrm{~b}$ painting process flowchart (remain). 


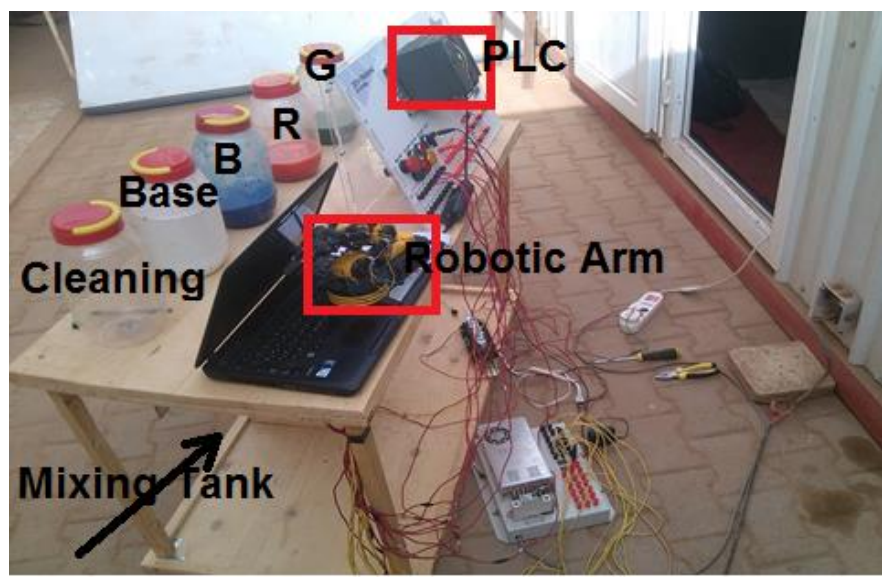

Fig. 5a Final Implementation Prototype.

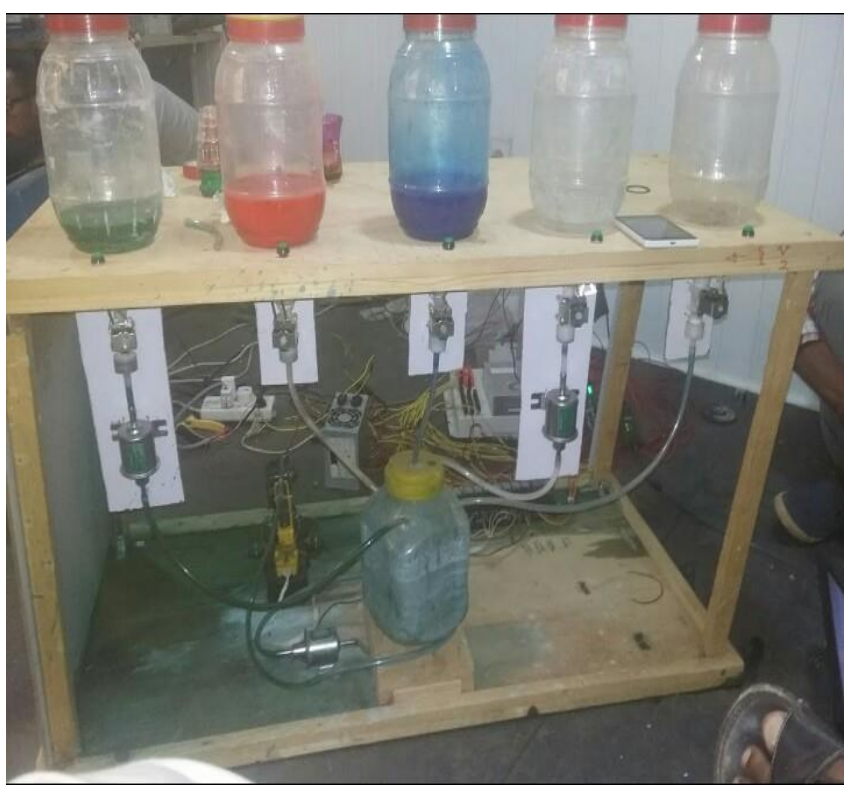

Fig. 5b Final Implementation Prototype.

\section{CONCLUSION}

In this paper, mixing and automatically painting machine has been implemented. The task of the machine orders a color from a user through HMI and mixes this color and paint a certain piece with a robotic arm. Mixing process and painting controlled with S7-300 PLC.

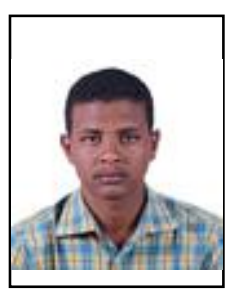

Kamal M.Alnetifa, was born in Sudan 1994, obtained B. SC in Electrical and Electronics Engineering from Omdurman Islamic University O.I.U on July 2017. He was teaching assistant in O.I.U faculty of Engineering science and Engineer in Sudanese Electricity Transmission Company SETC.

\section{ACKNOWLEDGMENT}

Authors wish to thank department of Electrical and Electronics in Omdurman Islamic University and everyone participate to accomplish this work.

And special thanks to Zeta Automation company for providing the PLC and open its labs to us to accomplish this research. Thank you all.

\section{REFERENCES}

[1] L. Schiop and M. Gaiceanu, "Mathematical Modelling of Color Mixing Process and PLC Control Implementation by Using Human Machine Interface", in International Symposium on

[2] Electrical and Electronics Engineering (ISEEE), 2010, pp. 165-170.

[3] D. Kandray, Programmable automation technologies. New York, N.Y.: Industrial Press, 2010.

[4] A. Hassen, S. Abd Elgadir, O. Omer and M. Abd Elhamid, "Automatic Control System of Mixing Color Machine", Bachelor, Omdurman Islamic University, 2016.

[5] Siemens, "Programmable Logic Controller", CPU 314C- 2 PN/DP datasheet, Mar. 2008.

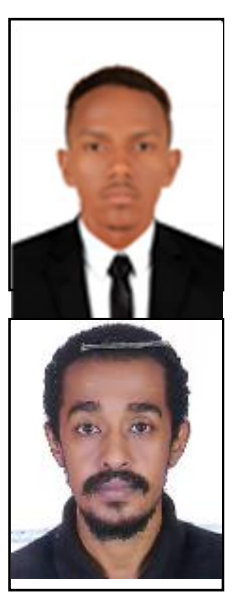

Abdalftah H. Mohammed, was born in Sudan 1994, obtained B. SC in Electrical and Electronics Engineering from Omdurman Islamic University O.I.U on July 2017. He was teaching assistant in O.I.U faculty of Engineering science and Engineer in Sudanese Electricity Transmission Company SETC.

Y M. Alkasim, was born in Yemen 1989, obtained B. Sc in Electrical and Electronics from Omdurman Islamic University O.I.U on June 2010 and M. Sc on Electrical Engineering (Communications) from Karary University on October 2013, Now Ph.D student in Karary University.

He was tutor in O.I.U the researcher in Sudan Technical Center in Communication department, then Lecturer in O.I.U again. As part time researcher he worked for Institute of Space Research and Aerospace ISRA. 